\title{
Genç Erkek Basketbolcularda Yapılan Farklı Isınma Yöntemlerinin Bazı Performans Parametreleri Üzerine Akut Etkisi
}

\author{
Acute Effect on Some Performance Parameters of Different Warm-Up \\ Methods in Young Men Basketball
}

\author{
${ }^{1}$ Erhan IŞIKDEMIR \\ ${ }^{1}$ Serkan UZLAŞIR \\ ${ }^{2}$ Yusuf KÖKLÜ
}

\section{Yazıșma Adresi \\ Corresponding Address:}

Arş. Gör. Erhan IŞIKDEMIR

ORCID: 0000-0002-4443-2222

Nevşehir Hacı Bektaş Veli Üniversitesi, Spor Bilimleri ve Teknolojisi Yüksekokulu, Antrenörlük Eğitimi Bölümü

E-posta:

erhanisikdemir20@gmail.com

\section{Öz}

Bu çalışmanın amacı genç erkek basketbolcularda yapılan basketbola özgü dinamik ısınma ve FIFA+11 ısınma programlarının germe kısalma döngüsü (GKD), dikey sıçrama (DS) yüksekliği ve yön değiştirmeli koşu (YDK) performansına akut etkisinin incelenmesidir. Araştırma grubunu 12 genç erkek basketbolcu (yaş ortalaması 15,7 \pm 1,8 (yıl); boy uzunluğu 170,3 \pm 7,2 (cm); vücut ağırlığı $67 \pm 14,0(\mathrm{~kg})$; antrenman yaşı $3,6 \pm 1,7$ (yıl) oluşturmaktadır. Çalışmanın ilk iki günü basketbola özgü dinamik ısınma ve FIFA+11 ısınma programı ile yapılacak olan ölçümlere ilişkin uyum antrenmanları uygulanmıştır. Birinci gün bir grup basketbola özgü dinamik ısınma, bir gurup FIFA+11 ısınma programını uygularken, ikinci ölçüm gününde gruplar yer değiştirmiştir. Her iki ısınma prosedüründen sonra 4 dakika dinlenme ve devamında sırasıyla GKD düzeyi ölçülmüş, devamında DS ve YDK testi yapılmıştır. Ölçümler Optojump sistemi ile kayıt altına alınmıştır. Yapılan ısınma protokollerinin performans üzerine olan etkisini karşılaştırmak için parametrik testlerden iliş̧ili Örneklemler için T-Test, GKD ile DS ve YDK arasındaki ilişkiye Pearson Korelasyon testi ile bakılmıştır. Çalışma sonucunda, basketbola özgü dinamik ısınma ve FIFA+11 ısınma programı sonrasında elde edilen performans parametreleri arasında GKD ve DS için istatistiksel olarak anlamlı bir farklılık bulunurken ( $p>0.05$ ), YDK performansı için fark bulunamamıştır. FIFA+11 ısınma programı sonrasında GKD ile DS ve YDK performansı arasında istatistiksel olarak yüksek düzeyde bir ilişki vardır $(p<0.01)$. Bu çalışmada, FIFA+11 ısınma programının GKD'yi olumlu yönde etkilediği tespit edilmiştir. Sonuç olarak antrenörlerin içerisinde patlayıcı hareketler içeren sıçrama, sprint özelliklerine yönelik yapılan çalışmalar öncesinde nöromüsküler bir ısınma yöntemi kullanması önerilebilir.

Anahtar Kelimeler: Isınma, Germe kısalma döngüsü, Dikey sıçrama, Yön değiştirmel koşu

\section{ABSTRACT}

The aim of this study is to evaulate the effects of dynamic warm-up and FIFA +11 warm-up programs, stretching-shortening cycle (SSC), vertical jump (VJ) height and change of direction running (COD) performance in young male basketball players. Twelve young male basketball players participated in this studuy (age $15.7 \pm 1.8$; height $170.3 \pm 7.2$; weight $67 \pm 14.0$; training age $3.6 \pm 1.7$ ). In the first two days of the study, basketball-specific warm-up were applied regarding the measurements to be made with the FIFA+11 warm-up program. On the first day, a group of basketball-specific dynamic warm-up applied a group of FIFA+11 warm-up programs, and then the second measurement day the groups were displaced. After both warm-up procedures, 4 minutes of rest, followed by SSC, VJ, and COD test, respectively. Measurements were recorded with the Optojump system. In order to compare the effect of warming protocols on performance, paired simple t-test, which is one of the parametric tests, was examined by the pearson correlation test between the SSC and VJ and the COD. As a result of the study, there are statistically significant difference in the SSC and VJ performance parameters obtained after basketball-specific dynamic warm-up and FIFA+11 warm-up program. $(p<.05)$, but there isn't statically difference in COD performance. After FIFA+11 warm-up program, there is a statistically high relationship between SSC and VJ performance and COD performance $(p<0.01)$. This study suggest that the FIFA+11 warm-up program had a positive effect on SSC. As a result, it may be suggested that coaches use a neuromuscular warm-up method prior to the studies on explosive movements that involve explosive movements and sprint features.

Keywords: Warm-up, Stretch-shortening cycyle, Counter movement jump, Chance of direction running 


\section{GíRIŞ}

Basketbol oyunu yapısı itibariyle aerobik tabanlı bir branş olup (Delextrat ve Cohend, 2009; Meckell ve ark., 2009; Metaxas ve ark., 2009) içerisinde yürüme, durma, orta ve düşük şiddetli koşular ile ribaunt, blok, şut gibi beceriler için çok sık kullanılan sıçrama, ani dönüşler, driplingler, hücumda ve geriye dönüşte sprintlerin sıklıkla kullanıldığı bir performans sporudur (Alemdaroğlu, 2011). Oyun içerisinde gereksinim duyulan ve sıklıkla kullanılan patlayıcı kuvvet gereksinimi olan hareketler sırasında patlayıcı hareket içeren sıçrama, ani dönüşler, ani hızlanma ve durma gibi aksiyonların gerçekleştirilebilmesi için kas kuvveti oldukça önemlidir (Pliauga ve ark., 2015; Alemdaroğlu, 2012; Erculj ve ark., 2010). Çünkü bir oyuncu müsabaka anında en az 50 sıçrama ile beraber oyunun yaklaşık \%10' 'luk zaman dilimini oluşturan 10-20 m' 'lik doğrusal ve yön değiş̧irmeli yüksek şiddetli koşulara maruz kalmaktadır (Drinkwater ve ark., 2008). Oyun içerisinde tekrar eden iyi bir sıçrama ile oyun anında hızlı yer değiştirme becerisi diğer teknik eylemlerle birleştiğinde savunma ve hücum organizasyonları içerisinde yapılan hareketin etkili bir şekilde ortaya çıkmasında oldukça önemlidir (Pliauga ve ark.,2015). Yapısı gereği basketbolda sıçramalar devamında yere düşüşs sonrası dönüşler ve hızlı geriye koşmalar, topa hamle gerektiren patlayıcı kuvvet gereksinimi yüksek olan birden fazla hareketle bileşik yapıda gerçekleşebilmektedir. Hareket sırasında Eksantrik fazdan (uzama) konsantrik faza (kısalma) geçişin hızlı olması ve hızlanma-yavaşlama hareketleri sırasında kuvvet aktarımının doğru bir şekilde transferinin sağlanması hem hızı hem de gücü arttıran önemli bir unsur olarak görülmektedir (Uzlaşır ve Erden, 2016). Bu noktada kasta meydana gelen GKD düzeyi hareketin etkili bir şekilde yapılması etkilemektedir.

GKD, kas-tendon kavşağının aktif uzamasıyla oluşan eksantrik kasılma boyunca elastik gerilim enerjisini depolayarak ani başarılı konsantrik harekete dönüştürülmesi olarak karakterize edilir (Komi, 1984; Rice ve ark., 2017) Tek konsantrik aktiviteye göre eksentrik ve konsantrik hareketin meydana getirdiği hareket daha fazla enerji oluş̧urur (Komi ve Nicol, 2000). Aslında GKD nöromuskuler sistemde reaksiyon artırımı için eksitabilite oranın artmasını sağlar. Ayrıca aşil tendonu (AT) alt ekstremite fonksiyonunun önemli bir yere sahiptir. Biomekaniksel olarak bakıldığında, AT ve kasları (m.soleus ve m.gastrocnemius) birçok aktivitede darbe yükünü absorbe eden ilk yapılardır. Bu dokuların dış kuvvet tarafından deforme edildiklerinde enerjiyi saklamaları ve gerildikten sonra geri tepme kabiliyetleri özellikle önemlidir (Huijin, 1992; Komi ve Nicol, 2000). GKD performansının ve pliyometrik performansın ölçülmesi, RSI (Reactive Strength Index) değeri kasın eksentrikten konsentrik kasılmaya hızlı geçebilme yeteneği olarak tanımlanır ve GKD düzeyini ifade eder. (Youg, 1995; Flanagan ve Harrison, 2007). Elde edilen RSI düzeyi, sporcuların kas sertlik düzeyleri hakkında bilgi verir. Sporcu maksimum sürat derecesini geliştirmek istiyor ise ilk yapacağı GKD süresini artırmak olmalıdır ki bu da pliyometrik eğitimde kontak zamanını azaltarak mümkün olabilir. GKD, RSI birimi ile değerlendirilir ve birimi metre/saniye $(\mathrm{m} / \mathrm{sn})$ olarak ifade edilir. RSI değerlendirilmesi, sporcuların hangi koşullarda egzersize devam ettirilip ettirilmeyeceğini tespit etmek için yapıllır. Uygun sıçrama yüksekliği tespit edilir. Çok yüksek düşme seviyesinde çalışmak pliyometrik eğitimin verimini düşürür, performansı azaltır ve sporcunun güvenilirliğini tehlikeye sokar. GKD bu sebeplerle koruyucu rehabilitasyonun vazgeçilmez bir parçası olarak düşünülmelidir (Uzlaşır, 2016).

Oyun içerisinde patlayıcı güç, hız ve çeviklik, toplu-topsuz hareketlerin doğru bir şekilde uygulanabilmesi açısından basketbol branşı için son derece önemlidir (Erculj ve ark., 2010). Bu noktada uygulama öncesi etkili bir 1sınma programı hazırlamak ve sporcuları sakatlıklara karşı koruyucu nitelikte ısınma uygulamalarını tercih etmek oldukça önemlidir (Behm ve Chaouachi, 2011; Bishop, 2003). Çünkü basketbol branşına baktığımızda yaşanan sakatlıkların ayak bileği $(\% 39,7)$, diz $(\% 14,7)$, baş, boyun ve yüz $(\% 13,6)$, kol ve el $(\% 9,6)$, kalça, uyluk ve üst bacak $(\% 8,4)$ bölgeleri olduğu görülmektedir (Borowski ve ark., 2008). Bu. FIFA+11 nöromusküler isınma protokolü bu tarz sorunların azaltılması ve performans verimliliğinin arttırılması için kullanılabilecek bir uygulama olabilir. Özellikle de basketbol oyun yapısı 
içerisinde farklı kas guruplarının antrene edilmesi ve müsabakaya hazırlanmada nöromüsküler 1sınma protokolleri tercih edilebilir.

Yapılan çalışmalara bakıldığında basketbolda farklı statik ve dinamik ısınma egzersizlerinin farklı performans parametreleri üzerine etkisinin incelendiği çalışmalar olsa da (Stevanovic ve ark., 2019; Holt ve Lambourne, 2008); FIFA+11 nöromusküler 1sınma ile basketbola özgü dinamik ısınmanın performans parametrelerine etkisine yönelik çalışmalara çok az yer verilmiştir (Longo ve ark., 2012). Bu yüzden çalışmanın amacı da; genç erkek basketbolcularda yapılan, basketbola özgü dinamik ısınma ile FIFA+11 nöromüsküler 1sınma protokollerinin GKD düzeyine, DS ve YDK performansına olan etkilerinin karşılaştırılması ve her iki ısınma protokolü sonrasında ortaya çıkan GKD ile DS ve YDK performansı arasındaki ilişki düzeyinin incelenmesidir.

\section{YÖNTEM}

Araştırma Grubu: Araştırma grubunu Nevşehir ili, Gençlik ve Spor Hizmetleri spor kulübünde, en az üç yıldır

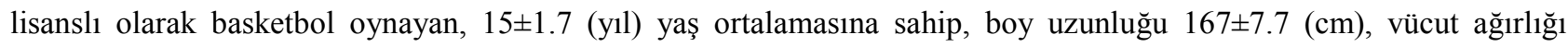
$60.4 \pm 14,7$ (kg) olan 12 erkek basketbolcu oluşturmaktadır (tablo 1). Çalışma öncesinde sporculara veli onam formu imzalatılmış olup, testler sırasında karşılaşılabilecek tüm olası durumlar detaylı olarak aktarılmıştır. Deney grubunu oluşturan sporcular test protokolü dışında farklı bir uygulama ya da sakatlık durumu ile karşılaşmaları halinde kendi istekleriyle çalışmadan ayrılma imkanı sunulmuştur. Bununla birlikte test protokolünü oluşturan hareketleri doğru bir hareket akışı içerisinde yapamayan ve hareketleri uygulamada zorluk yaşayan sporculara ait veriler değerlendirme dışı tutulmuştur. Çalışmanın yürütülmesi için Nevşehir Hacı Bektaş Veli Üniversitesi Etik Kurul Biriminden izin alınmıştır. (Tarih:10.10.2019 ve No:2019.10.125)

Tablo 1. Araştırma Grubuna ( $\mathrm{n}=12)$ Ait Tanımlayıcı Değerler

\begin{tabular}{ccc}
\hline & X & Ss. $( \pm)$ \\
\hline Yaş (yıl) & 15,75 & 1,86 \\
Boy Uzunluğu (cm) & 170,33 & 7,22 \\
Vücut Ağırı̆ı̆̆ (kg) & 67,32 & 14,03 \\
Antrenman Yaşı (yıl) & 3,66 & 1,72 \\
\hline
\end{tabular}

*Ss: Standart Sapma X: ortalama

İşlem Yolu: Bu çalışmada veriler 4 aşamalı olarak, birbirini takip eden günlerde, test günleri arasında bir gün dinlenme arası verilerek toplanmıştır. Birinci aşamada test protokolü tanıtılmış ve çalışma yöntemi anlatılmıştır. İkinci aşamada ise araştırma grubuna ait boy uzunluğu ve vücut ağırlığı ölçümleri yapılarak, Rastgele yöntemle randomize bir şekilde iki gruba ayrılmıştır. Devamında her iki grup için her iki ısınma protokolü de birer gün arayla gruplara atletik performans antrenörü eşliğinde uygulamalı olarak gösterilmiştir. Üçüncü aşama A grubu basketbola özgü dinamik ısınma, B grubu FIFA+11 nöromüsküler 1sınma protokolünü uygulamış ve devamında 4 dakika dinlenme verilerek GKD düzeyine bakılmış, devamında DS ve YDK testlerini uygulamıştır. Dördüncü aşamada ise iki grup yer değiştirmiş ve bir gün önceki protokol aynı şekilde sırasıyla uygulanmıştır (resim 1). Testler arasında 30 saniye dinlenme süreleri verilmiştir. Ölçüm süresince katılımcılar test süresince herhangi bir antrenman ya da müsabakaya katılmamıştır. Çalışmaya ilişkin tüm veriler Gençlik ve Spor Hizmetlerine bağlı spor salonunda günün aynı saatlerinde (16:00-18:00) alınmıştır. Test süresince standart bir değerlendirme yapabilmek için ölçümler aynı kişi tarafından kontrol edilmiş ve uygulama süreci yönetilmiştir. 


\section{TEST UYGULAMASI}

\begin{tabular}{|c|c|c|c|c|c|c|}
\hline 1.GÜN & 2.GÜN & 3.GÜN & & 4.GÜN & & 5.GÜN \\
\hline \multirow{8}{*}{$\begin{array}{l}\text { Araştırmaya } \\
\text { Yönelik } \\
\text { Açılklamaların } \\
\text { Yapılması }\end{array}$} & Antropometrik & Isınma & \multirow{4}{*}{ 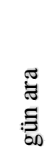 } & A grubu= & & $\mathrm{B}$ grubu= \\
\hline & Ölçüm ler & Protokollerine & & Dinamik & & Dinamik \\
\hline & $\mathrm{Ve}$ & Yönelik & & Isınma+Test & 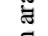 & Isınma+Test \\
\hline & Isınma & Adaptasyon & & & : ह్ & \\
\hline & Protokollerine & Uygulaması & - & $\mathrm{B}$ grubu= & - & $\mathrm{A}$ grubu= \\
\hline & Yönelik & ve & & FIFA+11 & & FIFA+11 \\
\hline & Adaptasyon & Testlerin & & Nöromusküler & & Nöromusküler \\
\hline & Uygulamas1 & Tanitılmas1 & & Isınma+ Test & & Isınma+ Test \\
\hline
\end{tabular}

\section{Resim 1. Test Uygulama Yolu}

Boy uzunluğu ve vücut ăğırlı̆̆ı: Katılımcılara ait boy uzunluğu duvara monte edilmiş mezura yöntemiyle anatomik duruş pozisyonları gözetilerek yapılmıştır. Vücut ağırlığı ise \pm 0.1 hassaslık düzeyine sahip holtain marka baskül yardımıyla, spor kıyafetler ile ayakkabısız olarak yapılmışıı.

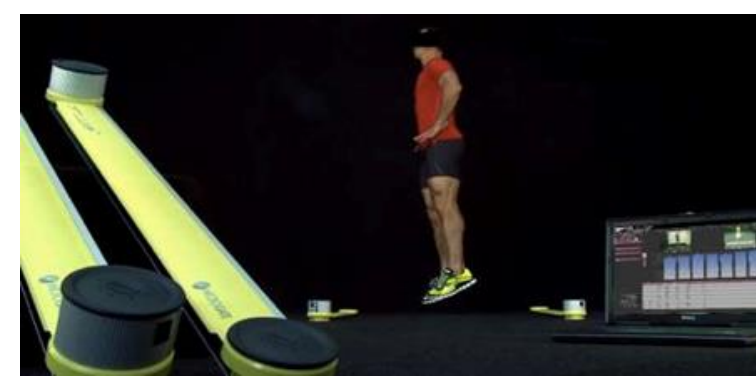

\section{Resim 2. GKD Ölçümü}

RKİ (reaktif kuvvet indeksi) de ğeri: Yapılan ısınma protokolü sonrasında sporcu belirlenmiş alanda yer alan Optojump (Microgate, İtalya) barlarının dışında eller belde pozisyon alarak, cihazdan gelen ilk sinyal sesi ile dizler tam ekstansiyonda iki OptoJump cihazının arasına sıçrayarak, aralıksız arka arkaya dizleri bükmeden 7 adet sıçrama gerçekleştirmiştir (resim 2). Bitiş sinyal sesi ile birlikte veri alımı kesilmiş ve denek belirlenen alanın dışına çıkması istenmiştir (Uzlaşır ve ark., 2016). Gastrocnemius kasına ait GKD değeri, 7 adet sıçramanın ortalama sıçrama yüksekliğinin yere düşme zamanına bölünmesi ile cihaz tarafından otomatik olarak hesaplanmaktadır. Tüm veriler ölçüm sırasında m/sn birimi ile OptoJump cihazı tarafından kaydedilmiştir (Young, 1995). Ölçümler 30 saniye aralıklarla 2 defa tekrarlanmış en iyi skor değerlendirmeye alınmıştır. Elde edilen ölçüm sırasında "Sıçrama Yüksekliği = (Havada kalma

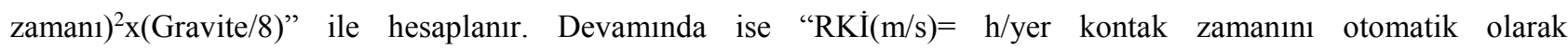
hesaplamaktadır.

Dikey sıçrama: Dikey sıçrama testi, karşılıklı olarak yerleştirilmiş iki OptoJump (Microgate, İtalya) cihazının arasında denek hazır olduğunda gerçekleştirilmiştir. Sporcu test sırasında eller belde, ayaklar yere sabit bir şekilde hazır olduğunda kısa bir yere çökme hareketi ile beraber yukarıya doğru kendisini firlatır (resim 3). Sporcunun sıçrama anında ellerini bırakması, dizini ya da ayaklarını yukarıya, yana doğru açması veya çekmesi hata olarak kabul edilmiş ve ölçüm geçersiz sayılmıştır. Ölçüm 30 saniye aralıklar ile iki kez tekrarlanarak ve en iyi sıçrama yüksekliği değerlendirmeye alınmıştır. 


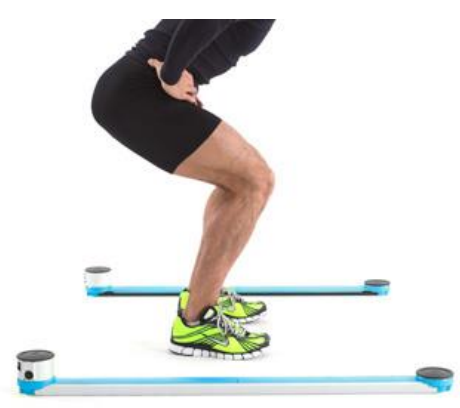

Resim 3 OptoJump-Dikey Sıçrama Testi

Yön değiştirmeli koşu testi: Test $20 \mathrm{~m}$ uzunluğunda, ilk $5 \mathrm{~m}$ sonunda $90^{\circ}$ 'lik dönüşün olduğu bir parkurda yapılır (resim 4). Denek başlangıç noktası olarak belirlenmiş noktada, fotosele $30 \mathrm{~cm}$ uzaklıkta yer alan çizgiye paralel bir pozisyonda bekler ve hazır olduğunda dışarıdan herhangi bir komut almadan A noktasında B noktasına (5m), B noktasından C noktasına (15m) olacak şekilde $20 \mathrm{~m}$ mesafeyi fotosellerin arasından geçerek testi tamamlamıştır. Test 30 saniye aralıklar ile iki kez yapılmış ve en iyi sprint zamanı değerlendirilmeye alınmıştır (Resim 3).

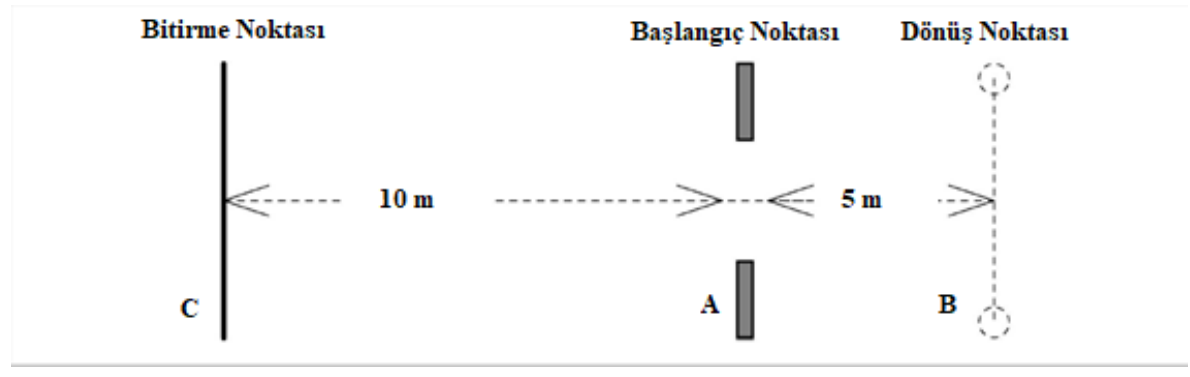

\section{Resim 4. 20m Yön Değiştirmeli Koşu Testi}

Dinamik ısınma prosedürü: Dinamik 1sınma protokolü üç bölümden oluşturulmuştur. Birinci bölümde 5 dakikalık düşük tempoda koşu, ikinci bölümde üst ekstremite için 6 farklı hareket; üçüncü bölümde alt ekstremiteye yönelik 8 farklı hareketten oluşturulmuştur. Alt ve üst ekstremiteye yönelik hareketler 10m belirlenmiş bir alan içerisinde hareket sırasına göre atletik performans antrenörü eşliğinde uygulanmıştır (Şekil 1). Toplamda ısınma süresi dinlenme süreleri ile birlikte 17 dakika olarak ayarlanmıştır. Bölümler arasında 1 dakika pasif dinlenme uygulanmıştır.

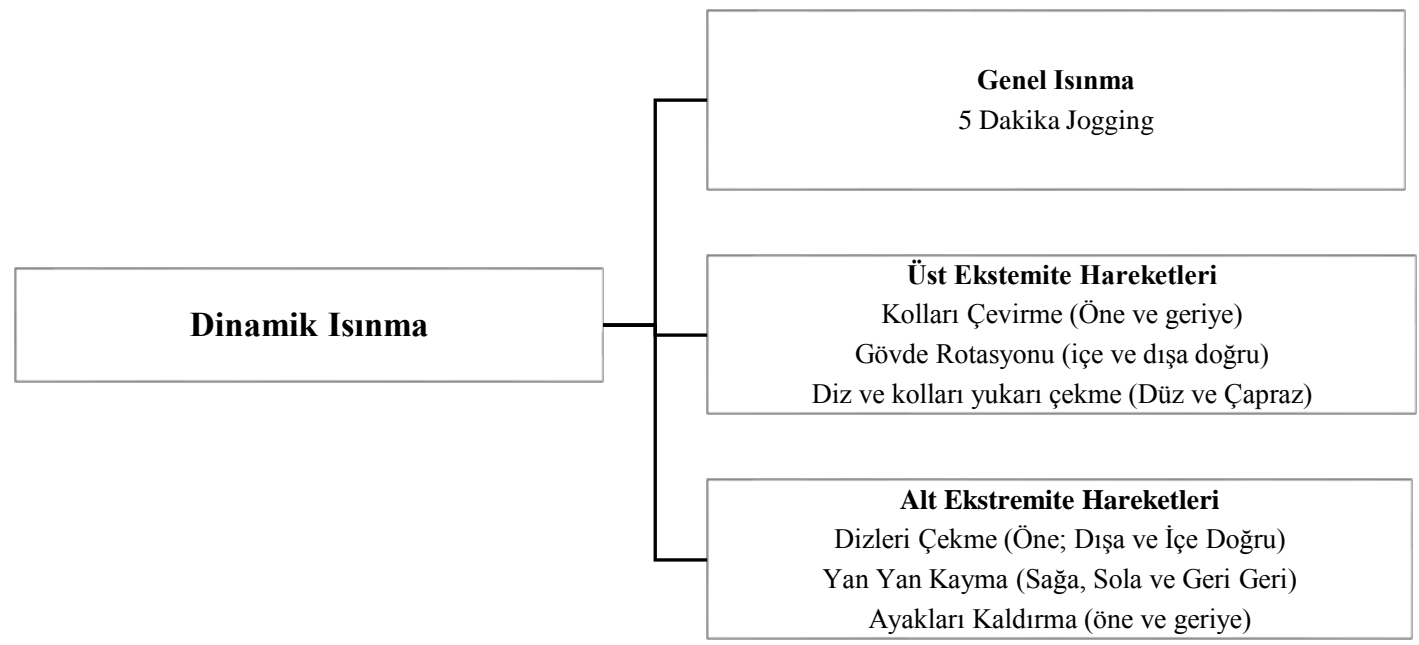

Şekil 1. Dinamik Isınma Protokolü 


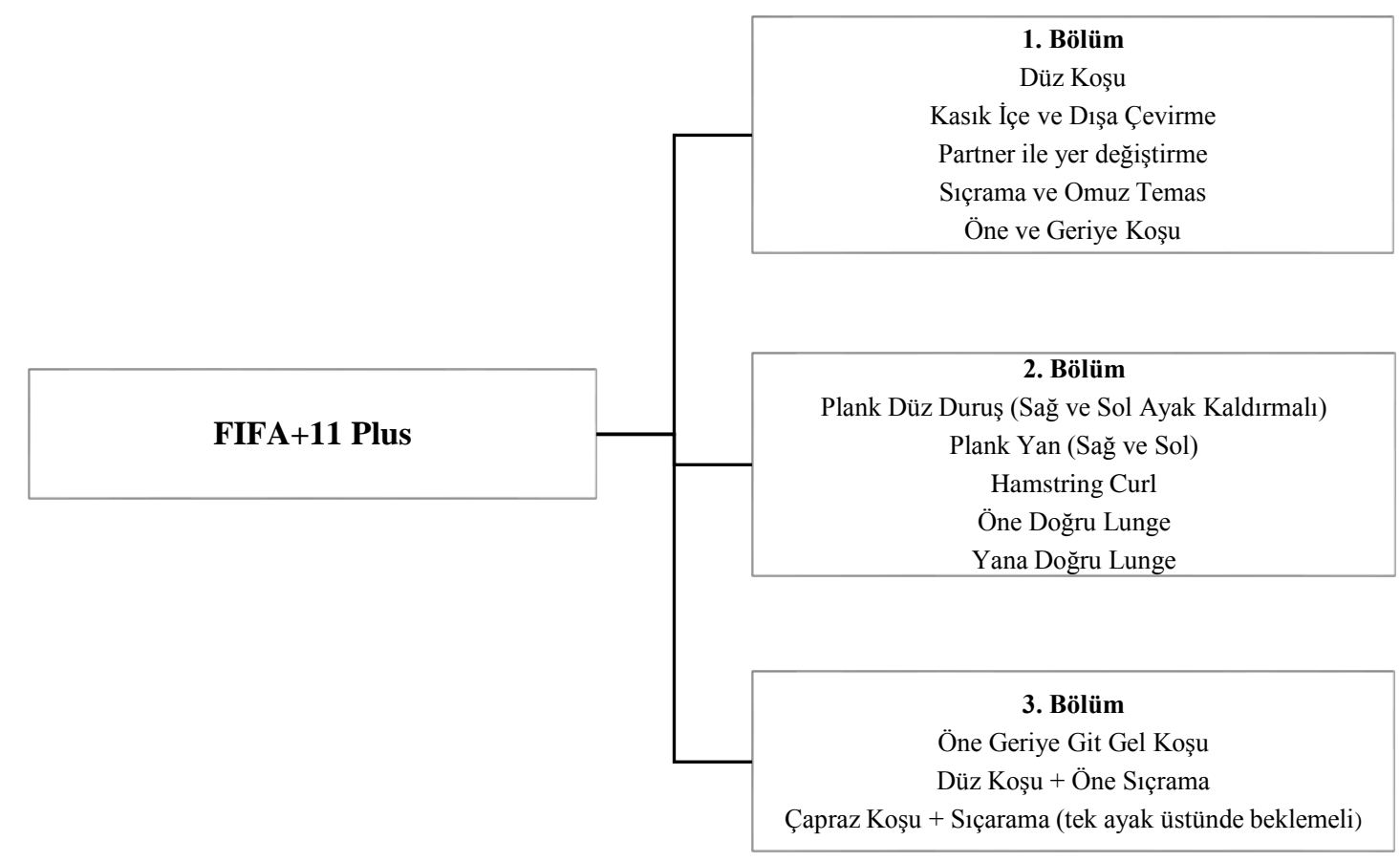

Şekil 2. FIFA+11 Isınma Protokolü

FIFA+11 Isınma Programı: FIFA+11 1sınma protokolü zorluk seviyesi gözetilerek, spor fizyoterapisti ve atletik performans antrenörü eşliğinde belirlenmiştir. Isınma protokolü 3 aşamalı olarak gerçekleştirilmiştir. Birinci bölümde dinamik ısınma, ikinci bölümde statik kuvvet hareketleri, üçüncü bölümde pliyometrik hareketlerden oluşmaktadır (şekil 2.). Protokol belirlenmiş 20 metre uzunluğunda bir alan içerisinde atletik performans antrenörü eşliğinde uygulanmıştır Bölümler arasında geçişlerde 1 dakika pasif dinlenme uygulanmıştır. Isınma protokolü dinlenme süreleri ile birlikte toplam süresi 17 dakika olarak hesaplanmıştır.

\section{Veri Toplama Araçları:}

Optojump: DS testi sırasında optik ölçüm yapabilen bir algılayıcısı ve bir vericisi olan 96 led'lik bir sisteme sahip olan OptoJump kullanılmıştır. Cihaz ile test sırasında yere düşme zamanı, havada kalma zamanı, hız, akselerasyon, adım sayısı, adım uzunluğu, adım zamanı, güç, gibi verileri ölçülebilmesini sağlamaktadır (Uzlaşır ve ark., 2016)

Microgate witty fotosel: YDK testleri sırasında verilerin toplaması için kablosuz 0.01 hassas düzeyinde ölçüm yapabilen Telemetrik Fotoselli Kronometre (Microgate Witty, ABD) kullanılmıştır (Resim 4).

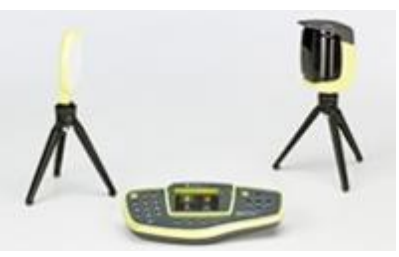

Resim 5. Microgate Witty Fotosel

Verilerin Analizi: İstatiksel işlemler için SPSS-22 paket programı kullanılmıştır. Yapılan iki farklı 1sınma sonrasında alınan GKD, DS ve YDK testi değerlerine ilişkin ortalama ve standart sapma değerleri hesaplanarak verilmiştir. Verilerin 
homojenliği için basıklık çarpıklık testi uygulanmıştır. Tüm verilerin -1 ile +1 değerleri arasında olduğu görülmüştür. Verilerin homojen olarak dağılması sonrasında iki ısınma protokolü sonrasında yapılan ölçümler arasındaki farka bakmak için ilişkili örneklemler için T-Test; iki ısınma protokolü sonrasında ortaya çıkan GKD düzeyi ile DS ve YDK testi skorları arasındaki ilişki düzeyine bakmak için Pearson Korelasyon testi uygulanmıştır. Anlamlılık düzeyi p<0.05 olarak kabul edilmiştir.

\section{BULGULAR}

Yapılan ölçümler sonucunda, elde edilen bulgulara ilişkin istatistiksel sonuçlar tablolar halinde verilmiştir.

Tablo 2. İlişkili Örneklemler İçin T-Test Skorları

\begin{tabular}{|c|c|c|c|c|c|c|c|}
\hline & $\mathbf{X}$ & Ss & Min. & $\operatorname{Max}$ & $\mathbf{t}$ & Df & $\mathbf{p}$ \\
\hline DI_GKD (m/sn) & ,98 & .64 & .29 & 1.89 & \multirow{2}{*}{$-2,94$} & \multirow{2}{*}{11} & \multirow{2}{*}{$.01^{*}$} \\
\hline FIFA+11_GKD (m/sn) & 1,28 & .63 & .44 & 2,87 & & & \\
\hline DI_DS (cm) & 28.83 & 7.61 & 18.80 & 37.80 & \multirow{2}{*}{$-2,48$} & \multirow{2}{*}{11} & \multirow{2}{*}{.03} \\
\hline FIFA+11_DS (cm) & 30.11 & 7.56 & 17.90 & 38.40 & & & \\
\hline DI_YDK (sn) & 4.58 & .39 & 4.02 & 5.27 & \multirow{2}{*}{1,21} & \multirow{2}{*}{11} & \multirow{2}{*}{.25} \\
\hline FIFA+11_YDK (sn) & 4.52 & .32 & 3.90 & 4.90 & & & \\
\hline
\end{tabular}

\#= DI_GKD, FIFA+11 GKD' den farklı; *=DI_DS, FIFA+11 DS dan farklı

Tablo 2'ye bakıldığında FIFA+11 1sınma programı sonrasında elde edilen performans değerleri için yapılan İlişkili Örneklem T-Test sonuçlarına göre DI ve FIFA+11 1sınma programı sonrasında elde edilen GKD düzeyi ve DS arasında istatiksel olarak anlamlı bir farklılık varken $(\mathrm{p}<0.05$ sırasılla 0.01;0.03). YDK performansları arasında istatiksel olarak anlamlı bir farklılık olmadığ 1 görülmektedir $(\mathrm{p}>0.05 ; 0,25)$.

Tablo 3. Korelasyon Analizi Sonuçları

\begin{tabular}{ccccc}
\hline & \multicolumn{2}{c}{ DİNAMIK ISINMA } & \multicolumn{2}{c}{ FIFA+11 } \\
\cline { 2 - 5 } GKD & DS & YDK & DS & YDK \\
&, $75^{* *}$ &,- 57 &, $90^{* *}$ &,$- 82^{* *}$ \\
\hline & & & \\
\hline
\end{tabular}

Tablo 3"'e bakıldığında dinamik ısınma sonrasında elde edilen yapılan korelasyon sonuçlarına göre; GKD düzeyi ile DS test sonuçları arasında yüksek düzeyde ilişki $(\mathrm{p}<0.01)$ bulunurken, YDK performansı arasında herhangi bir ilişki bulunmamıştır ( $>0.05)$. FIFA+11 1sınma programı sonrasında elde edilen GKD düzeyi ile DS arasında pozitif yönde yüksek ilişki ( $\mathrm{P}<0.01)$; YDK performansı arasında yüksek düzeyde negatif yönde ilişki bulunmuştur $(\mathrm{P}<0.01)$.

\section{TARTIŞMA}

Yapılan araştırmanın sonuçlarına bakıldığında İlişkili Örneklem T-Test sonuçlarına göre, iki farklı 1sınma yöntemi olarak kullanılan DI ve FIFA+11 1sınma protokolü sonrasında elde edilen GKD düzeyi ve DS performansları istatistiksel olarak anlamlı bir farklılık olduğu görülürken $(\mathrm{p}<.05)$, iki ısınma protokolü sonrasında elde edilen YDK performansı arasında istatistiksel olarak anlamlı bir farklılık olmadığı görülmektedir p<.05 (tablo 2). Korelasyon sonuçlarına bakıldığında ise DI sonrasında oluşan GKD düzeyi ile dikey sıçrama performansı arasında ( $p=.75)$ pozitif yönde 
istatistiksel olarak yüksek düzeyde korelasyon olduğu görülürken, yön değiştirmeli koşu performansı arasındaki korelasyon düzeyinin istatistiksel olarak anlamlı olmadığı görülmektedir (tablo 3). FIFA+11 1sınma programı sonrasında elde edilen GKD düzeyinin ise DS ile pozitif yönde ( $\mathrm{p}=.90)$, YDK performansı arasında negatif yönde ( $\mathrm{p}=-82)$ yüksek düzeyde korelasyon olduğu görülmektedir (tablo 3 ).

Yapılan literatür taramasında farklı ısınma protokollerinin performans çıktısı üzerine etkisini inceleyen çalışmalar olduğu görülmektedir. Ancak uygulanan ısınma yöntemleri açısından farklılıklar görülmektedir. Yapılan çalışmalara bakıldığında dinamik ve statik ısınma yöntemleri arasındaki farklılıklara odaklanmıştır.

Gabbet ve ark., (2008) genç basketbol oyuncuları üzerinde yaptığı araştırmada iki farklı dinamik ısınma sonucuna sporcuların dikey sıçrama, sprint, yön değiştirmeli koşu performansı ve reaktif çeviklik test skorları arasında istatistiksel olarak fark olmadığını ifade ederken, hem açık beceri hem de kapalı beceri hareketleri içerisinde barındıran ısınma türlerinin benzer sonuçlar ortaya çıkardığı ve bu ısınma türlerinin takım sporlarında kullanılabilir olduğunu belirtmiştir. Neto ve ark., (2017) yaptığı meta-analiz çalışmasının sonucu olarak FIFA+11 ısınma protokolü uygulanan gruplarda dikey sıçrama $(0.08-0.59 ; \mathrm{P}=0.14)$ ve sprint koşu performanslarında $(0.58-0.10 ; \mathrm{P}=0.17)$ istatistiksel olarak bir değişim olmadığını ifade etmiştir. Holt ve Lambourne (2008) ise yaptığı araştırmada 64 erkek futbolcu ile statik 1sınma protokolü ile üç farklı şekilde dizayn edilmiş dinamik ısınma protokolleri sonrasında dikey sıçrama performanslarını değerlendirmiş ve statik ısınma protokolü sonrasında elde edilen dikey sıçrama performansının diğer üç dinamik ısınma protokolüne göre düşük olduğunu ifade etmiştir. Needham ve ark., (2009) genç erkek futbolcularda yaptıkları araştırmada üç farklı 1sınma sonrasında verilen farklı dinlenme sürelerinden sonra dikey sıçrama ve 10-30 m sürat performansı değerlendirmesinde dinamik ısınma + vücut ağırlı̆ı̆ının \%20 sine denk gelen ek ağırlıkla yapılan 8 skuattan oluşan 1sınma protokolü sonrasında elde edilen dikey sıçrama performansının, dinamik ısınma ve statik ısınma sonrasında elde edilen performanstan daha iyi olduğunu ifade etmiştir, ancak benzer sonuçlar sprint performansı için gerçekleşmemiştir. Stevenovic ve ark. (2019) genç erkek basketbolcular üzerinde yaptıkları araştırma sonuçlarında branşa özgü ısınma yaklaşımının dikey sıçrama performansı üzerine negatif bir etkisinin olmadığını, nöromüsküler uyarılmışlık düzeyine ise aynı düzeyde etki etmediğini, dinamik ısınma ile kombine edilmiş topla 1sınma hareketlerinin güç çıktısı üzerine olumlu bir etkisi olmadığı ifade edilmiştir. Dinamik ve FIFA+11 nöromüsküler 1sınma arasında farklılıklarının olmasının nedeni üç farklı 1sınma türünde de uyarılan motor ünite sayısının harekete katılma düzeyinden kaynaklanmış olabileceği söylenebilir.

Germe kısalma döngüsünün, sürat, içerisinde yön değiştirme olan koşular, dikey ve yatayda yapılan sıçrama gibi performans bileşenlerinin geliştirilmesinde önemli bir payı olduğu, özellikle pliyometrik uygulamalarında ciddi anlamda germe kısalma döngüsüne etki ettiği ifade edilmektedir (Uzlaşır, 2016). Araştırmamızın sonuçlarından da anlaşılacağı gibi FIFA+11 isınma protokolü sonrasında oluşun GKD düzeyinin (1.28 m/sn.), DI sonrasında oluşan GKD düzeyinden (.98 m/sn) yüksek olduğu görülmüştür. FIFA+11 1sınma protokolü sonrasında değerlendirilen GKD düzeyi ile DS ve YDK performansı arasındaki yüksek ilişkinin olması eksantrik fazdan konsantrik faza geçerken patlayıcılık yetisine etki ettiği ve sıçrama sırasında özellikle yerde kalma süresini üzerinde etkili olduğu, bununda performansın daha iyi bir şekilde ortaya çıkmasına neden olduğu ifade edilebilir. Çünkü, GKD nin artması, kaslar arasında kuvvet aktarımının daha hızlı bir şekilde gerçekleşmesin ve yer ile olan kontak zamanı düşürerek nöromusküler sistemin yatayda kuvvet depolama ve üretme kapasitesinin arttırarak ürettiği kuvveti kullanabilme yeteneğini de arttırmaktadır (Brughelli ve Cronin 2008; Rumpf ve ark. 2013). GKD ve YDK performansı arasındaki negatif yönde yüksek ilişkinin çıkmasının buradaki durumdan kaynaklı olduğu düşünülmektedir. İnce (2020) genç voleybolcular üzerinden yaptı̆̆ı araştırmada da özellikle reaktif kuvvet indeksi değerlerinde meydan gelen artışın, smaç sıçrama testi arasındaki ilişki düzeyinin ( $\mathrm{r}=0.77)$ yüksek olduğunu ifade etmiştir. GKD’nde meydana gelebilecek düşüş, alt ekstremite de meydana gelen sertlik (stifness) düzeyini 
düşürdüğü ve bu durumun olası sakatlık riskini de arttırdığı bilinmektedir (Butler ve ark., 2003; Clansey ve ark., 2012; Dutto ve Smith, 2012; Girard ve ark., 2013 Magnan ve ark., 2014). Çalışma sonuçları da göstermiştir ki FIFA+11 1sınma protokolü GKD düzeyini üzerinde etkisi vardır. Buda olası sakatlık risklerinin azaltılmasına noktasında katkı sağlayabilir (Devenham ve ark., 2014) ve aynı zamanda aşil tendonuna binen yükler göz önünde bulundurulduğunda performans üzerinde olumlu katkısı olduğu söylenebilir (Rabita ve ark., 2008; Rosengarten ve ark., 2014). Buradan alacağımız bilgi ile özellikle aşil tendonuna ait patolojilere yaralanma olmadan nöromüsküler isınma yöntemleri kullanarak önlem alma şansımızı arttırabilir.

\section{SONUÇ ve ÖNERILERR}

Araştırma sonucunda elde edilen bulgular ve yapılan literatür karşılaştırması sonuçlarına göre, anaerobik güç gereksinimi olan hareketler için dinamik ısınma protokollerinin, statik olarak yapılan 1sınma protokollerine göre daha iyi performans sağladığı; FIFA+11 nöromüsküler ısınma protokolünün ise daha fazla motor üniteyi aktive edebilecek hareket türlerini barındırması performans üzerine daha fazla etkisi olduğu; bununla birlikte futbol, voleybol gibi sporlarda olduğu gibi basketbolda da hareketlerin çok yönlü olması ve patlayıcı hareketler içermesi, 1sınmada hareket seçimlerini oldukça önemli olduğu, özellikle FIFA+11 nöromüsküler 1sınma programının da bu noktada faydalı olabileceği söylenebilir. Yüksek güç çıktısı gerektiren çalışmalar öncesinde yapılacak bir dinamik ısınma yerine nöromüsküler ısınma yönteminin kullanılması performans verimliliğini arttırabileceği çalışma bulgularının bir sonucu olarak görülmektedir. Buna göre GKD" "nin geliştirilmesi, hareket geçişleri sırasında kuvvet aktarımını dengelemesi, daha fazla hareket genişliği sağlayarak etkili bir performans sergilenmesine katkı sağlayacağı için nöromüsküler 1sınmaların aktif olarak kullanılarak akut etkisine yönelik araştırmaların yapılması ve elde edilen sonuçlara bakılarak antrenörlerin içerisinde patlayıcı hareketler içeren sıçrama, sprint gibi performans bileşenlerine yönelik yapılan çalışmalar öncesinde nöromüsküler bir ısınma yöntemi kullanması önerilebilir.

\section{KAYNAKLAR}

1. Alemdaroğlu BU. (2012). The relationship between muscle strength, anaerobic performance, agility, sprint ability and vertical jump performance in professional basketball players. Journal of Human Kinetics, 31: 149-158.

2. Alemdaroğlu, BU. (2011). Basketbolda Farklı Oyuncu Sayılarıyla Oynanan Yarı Saha ve Tam Saha Oyunlarına Verilen Fizyolojik Cevapların Karşılaştırılması, Yüksek Lisans Tezi, Beden Eğitimi ve Spor Anabilim Dalı, Ankara Üniversitesi, Ankara.

3. Brughelli M, Cronin, J. (2008). Influence of running velocity on vertical, leg and joint stiffness: modelling and recommendations for future research. Sports Medicine, 38, 647-657.

4. Butler RJ, Crowell HP., Davis IM. (2003). Lower extremity stiffness: Implications for performance and injury. Clinical Biomechanic 18: 511-517.

5. Clansey AC, Hanlon M, Wallace ES., Lake MJ. (2012). Effects of fatigue on running mechanics associated with tibial stress fracture risk. Medicine Science Sports Exercise, 44: 1917-1923.

6. Debenham JR, Travers MJ, Gibson W, Campbell A, Allison GT. (2014). Achilles tendinopathy alters stretch-shortening cycle behaviour during a sub-maximal hopping task. Journal of Science Medicine Sports, doi:10.1016/j. jsams.2014.11.391.

7. Delextrat A, Cohen D. (2009). Strength, power, speed, and agility of women basketball players according to playing position. Journal of Strength and Conditioning Research. 23(7): 1974-1981.

8. Drinkwater EJ, Pyne JDB, Mckenna MJ. (2008). Design and interpretation of anthropometric and fitness testing of basketball players. Sports Medicine; 38(7): 565-578.

9. Dutto DJ, Smith GA. (2002). Changes in springmass characteristics during treadmill running to exhaustion. Medicine Science Sports Exercise, 34: 1324-1331. 
10. Erculj F, Blas M, and Bracic M. (2010). Physical demands on young elite european female basketball players with special reference to speed, agility, explosive strength, and take-off power. Journal of Strength and Condition Reseurch, 24 (11): 2970-2978.

11. Flanagan EP, Harrison AJ. (2007). Muscle dynamics differences between legs, in healthy adults. Journal of Strength and Condition Research, 21: 67-72.

12. Gabbett T, Sheppard JM, Pritchard-Peschek KR, Leverit MD, Aldred MJ. (2008) Influence of closed skill and open skill warm-ups on the performance of speed, change of direction speed, vertical jump, and reactive agility in team sport athletes. Journal of Strength and Conditioning Research, 22 (5).

13. Girard O, Millet GP, Slawinski J, Racinais S, Micallef JP. (2013). Changes in running mechanics and spring-mass behaviour during a 5$\mathrm{km}$ time trial. International Journal of Sports Medicine, 34: 832-840.

14. Holt BW, Lambourne K. (2008). The impact of different warm-up protocols on vertical jump performance in male collegiate athletes. Journal of Strength and Condition Research. Sep;22(5):1720, doi: 10.1519/JSC.0b013e31815f9d6a.

15. İnce İ. (2020). Investigation of relationship between reactive strength index and leg stiffness with some performance tests in 14-17 year age group volleyball players. The Journal of GERMENICA Physical Education And Sports Science, 1(1).

16. Komi PV. (1984). Physiological and biomechanical correlates of muscle function: effects of muscle structure and stretch-shortening cycle on force and speed. Exercise Sport Science Review, 12:81-121.

17. Komi PV, Nicol C. (2000). Stretch-Shortening Cycle of Muscle Function, Biomechanics in Sport. Blackwell Scientific Publications, Oxford, $87-102$.

18. Magnan B, Bondi M, Pierantoni S, Samaila E. (2014). The pathogenesis of achilles tendinopathy: a systematic review. Foot Ankle Surgery, 20: $154-159$.

19. Meckell Y, Casorla T, Eliakim A. (2009). The influence of basketball dribbling on repeated sprints. International Journal of Coaching Science, 3 (2): 43-56.

20. Metaxas,TI, Koutlianos N, Sendelides T, Mandroukas A. (2009). Preseason physi-ological profile of soccer and basketball players in different divisions. Journal of Strength and Conditioning Research, 23 (6): 1704-1713.

21. Neto GM, Conceicao CS, De Lima B, De Sousa CS, Carvalho VO, De Jesus FLA. (2017). Effects of the FIFA 11 training program on injury prevention and performance in football players: a systematic review and meta-analysis. Clinical Rehabilitation; 31(5):651-659. doi: 10.1177/0269215516675906 Epub 2016 Nov 3.

22. Oliver JL, De Ste Croix MB, Lloyd RS, Williams CA. (2014). Altered neuromus- cular control of leg stiffness following soccer-specific exercise. European Journal of Appled Physiology, 114: 2241-2249.

23. Pliauga V, Kamandulis S, Dargevičiūtė G, Jaszczanin J, Klizienė I, Stanislovaitienė J, Stanislovaitis A. (2015). The effect of a simulated basketball game on players' sprint and jump performance, temperature and muscle damage. Journal of Human Kinetics, 46(1):16775DOI: 0.1515/hukin-2015-0045.

24. Rabita G, Couturier A, Lambertz D. (2008). Influence of training background on the relationships between plantarflexor intrinsic stiffness and overall musculoskeletal stiffness during hopping. European Journal of Applied Physiology, 103: 163-171.

25. Rice PE, van Werkhoven H, Dejournette DJ, Gurchiek RD, Mackall JW, McBride JM. (2017). A comparison of musculo-articular stiffness and maximal isometric plantar flexion and knee extension force in dancers and untrained individuals. Journal of Dance Medicine Science, 21(4):144-150.

26. Rosengarten SD, Cook JL, Bryant AL, Cordy JT, Daffy J, Docking SI. (2014). Australian football players' Achilles tendons respond to game loads within 2 days: an ultrasound tissue characterisation (UTC) study. British Journal of Sports Medicine, doi:10.1136/bjsports-2013092713.

27. Rumpf MC, Cronin JB, Oliver JL, Hughes MG. (2013) Vertical and leg stiffness and stretch-shortening cyle change across maturation during maximal sprint running. Human Movement Science. 32,p:668-676.

28. Stevanovic VB, Jelic MB, Milanovic SD, Filipovic SR, Mikic MJ, Stojanovic MDM. (2019). Sport-specific warm-up attenuates static stretching- induced negative effects on vertical jump but not neuromuscular excitability in basketball players. Journal of Sports Science and Medicine, 18, 282-289.

29. Uzlaşır S, Erden Z. (2016). Profesyonel basketbol oyuncularında kinezyo bantlamanın gastrocnemius kasında germe-kısalma döngüsü üzerine etkisi. Journal of Exercise Therapy and Rehabilitation, 3(2):37-44.

30. Uzlaşır S. (2016). Basketbol Oyuncularında Farklı Kas Gruplarına Uygulanan Kinezyo Bantlamanın Performans Üzerine Etkisi, Yüksek Lisans Tezi, Hacettepe Üniversitesi, Ankara.

31. Young W. (1995). Laboratory strength assessment of athletes. New Studies in Athletics. 10, 88-96. 